in South America, it is calculated that the cost of the observatory would amount to 70,000 or 80,000 lire, of which 10,000 would be for instruments, and the remainder would provide three dwellinghouses, salaries of four scientists, two assistants, and two servants, food, \&c. This is calculated for an absence of sixteen months, twelve of which would be occupied in observations.

THE Geographical Society's Proceedings this month contains three papers relating to Africa, the first of which is Sir Bartle Frere's, on Temperate South Africa. This, as now printed, embodies some useful statistical information and is illustrated by a general map of South Africa. The other two papers bring some additions to our knowledge of the geography of West Africa, Mr. Comber giving a short sketch of his recent journeys in the interior of Congo, and Mr. Milum an account of his travels in the Niger region. The former is accompanied by an excellent map of the neighbourhood of San Salvador and of the course of the River Congo from Stanley Ponl to the sea. The final report of the Executive Committee of the African Exploration Fund is published, together with a statement of receipts and expenditure. In the Geographical Notes extracts are given from a letter by $\mathrm{Mr}$. Hore of Ujiji, on the long-continued rise of the waters of Lake Tanganyika, which he seems to connect with earthquake-movements. Mr. Hore is shortly about to return to England, so that we shall probably hear more on this subject before long. Among the other notes we may call attention to thcse on the River Okavango, the survey of Eastern Palestine, and the United States' Survey operations in the neighbourhood of Behring Strait. Increased attention, we note, is being paid to the proceedings of foreign geographical Societies, those of the French Society being yery fully reported.

M. Vossron, who, it will be remembered, spent some time in Burmah, and not long since read papers on that country before the French Greographical Societies, has lately gone to Egypt to take up the Vice-Consulship of Khartum. During his stay there he is to pay special attention to the slave trade, and to the best means of opening up commercial relations with the Sudan.

Capt. Serra-Carracioli left Naples on November 23, r88o, for the Bay of Assab, having undertaken a mission, under the auspices of the Club Africano, to inquire into the possibility of developing commerce there and with the natives of the interior The Club Africano is desirous of establishing pearl, mother-ofpearl, and sponge fisheries in the Bay of Assab. While funds are being raised for more extensive operations, this expedition is sent out to make a careful survey of the region, to form a depôt for further expeditions, whether commercial or scientific, and to make other preparations. The expense is expected not to exceed $600 l$. It is also stated that the Italian Geographical Society have made arrangements for the establishment of a meteorological station at the Bay of Assab. The October part of the Bolletino of the Italian Geographical Society contains a long and valuable memoir by Signor C. de Amezaga on Assab.

AT the last meeting of the Lyons Geographical Society M. Coillard gave an interesting account of his twenty years' experiences in South Africa. He was engaged for some time on a missionary expedition in the Upper Zambesi region, and was probably the means of saving Major Serpa Pinto's life, afterwards accompanying him in some of his explorations. As no particulars have yet been published of M. Coillard's geographical work in this region, it is to be boped that his paper will be given in full in the Lyons Society's Bulletin.

In last week's Missions Catholiques we have the concluding instalment of some interesting and useful papers iby the Bishop of Vancouver, entitled "Une Visite Pastorale dans le Territoire d'Alaska." Père Montiton's notes on the traditions and customs of the Sandwich Islands are also cuntinued.

THE January number of Good Words contains the first of a series of papers by Mr. Joseph Thomson on his experiences during his recent journey in East Central Africa. The present instalment deals with the preparatory journey which he made with $\mathrm{Mr}$ Keith Johnston to Usambara, and furnishes interesting notes on the country traversed.

The Alexandria Correspondent of the Daily News tells us that M. Chower, formerly a newspaper correspondent in Turkey, Kurdistan, Armenia, and Albania, started on December 3I, "to explore Africa from north to south, from Alexandria to the Cape of Good Hope." Bon voyage.

THE death is announced of Dr. Fr. Mook, the wrll.krowis African traveller, who accompanied Dr. E. Riebeck on his expedition, which started in August last for the East. Dr. Mook died at Jaffa shortly before Christmas.

WE have received parts 17 to 22 of the new edition of Stieler's Hand-Atlas, with three supplementary parts containing in eight sheets a very fine map of the Basin of the Mediterranean Sea.

THE Dutch Committee, which arranged the North Polar Expeditions of the last few years, held a general meeting at the Hague a short time ago, when the resolution was passed to collect funds for the organisation of a fourth Arctic expedition. In the meantime the Committee will endeavour to have a steamer built for this purpose.

\section{ON HEAT CONDUCTION IN HIGHLY RAREFIED AIR}

THE transfer of heat across air of different densities has been examined by various experim ntalists, the general result being that heat conduction is almost independent of pressure. Winkelmann (Pogg. Ann. 1875, 76) measured the velocity of cooling of a thermometer in a vessel filled with the gas to be examined. The difficulty of these experiments lies in the circum. stance that the cooling is caused not only by the conduction of the gas which surrounds the cooling body, but that also the currents of the gas and, above all, radiation play an important part. Winkelmann eliminated the action of currents by altering the pressure of the gas between 760 and I millim. (with decreasing pressure the action of gas currents becomes less); and he obtained data for eliminatirg the action of radiation by varying the dimensions of the outer ves el. He found that, whereas a lowering of the pressure from 760 to $9 \mathrm{r}^{\circ} 4$ millims. there was a change of only I' 4 per cent. in the value for the velocity of cooling, on further diminution of the pressure to 4.7 millims. there was a further decrease of is per cent., and this decrease continued when the pressure was further lowered to $I^{\circ} 92$ millim.

About the same time Kundt and Warburg (Pogg. Ann. 1874, 5) carried out similar experiments, increasing the exhaustion to much higher points, but without giving measurements of the pressure below I millim. They inclosed a thermometer in a glass bulb connected with a mercury pump, and heated it to a higher tem. perature than the highest point at which observations were to be taken; then left it to itself, and noted the time it took to fall through a certain number of degrees. They found that between ro millims. and I millim. the time of cooling from $60^{\circ}$ to $20^{\circ}$ was independent of the pressure; on the contrary, at I 50 millims. pressure the rate was one-and-a-half times as great as at 750 millims. Many precautions were taken to secure accuracy, but no measurements of higher exhaustions being given the resnlts lack quantitative value.

It appears, therefore, that a thermometer cools slower in a so. called vacuum than in air of atmospheric pressure. In dense air convection currents have a considerable share in the action, but the law of cooling in vacua so high that we may neglect convection has not to my knowledge been determined. Some years ago Prof. Stokes suggested to me to examine this point, but finding that Kundt and Warburg were working in the same direction it was not thought worth going over the same ground, and the experiments were only tried up to a certain point, and then set aside. The data which these experiments wonld have given are now required for the discussion of some results on the viscosity of gases, which I hope to lay before the Society in the course of a few weeks; I have therefore completed them so as to embody the results in the form of a short paper.

An accurate thermometer with pretty open scale was inclosed in a $\mathrm{I} \frac{1}{2}$ inch glass globe, the bulb of the thermometer being in the centre, and the stem being inclosed in the tube leading from the glass globe to the pump.

Experiments were tried in two ways:-

I. The glass globe (at the various exhaustions) was immersed in nearly boiling water, and when the temperature was stationary it was taken out, wiped dry, and allowed to cool in the air, the number of seconds occupied for each sink of $5^{\circ}$ being noted.

II. The globe was first brought to a uniform temperature in a vessel of water at $25^{\circ}$, and was then suddenly plunged into a large vessel of water at $65^{\circ}$. The bulk of hot water was such that the temperature remained sensibly the same during the continuance of each experiment. The number of seconds required for the thermometer to rise from $25^{\circ}$ to $50^{\circ}$ was registered as in the first case.

${ }^{I}$ Abstract of a Paper read before the Royal Society by William Crookes, F. R.S., December 16 , 1880 . 
It was found that the second form of experiment gave the most uniform results; the method by cooling being less accurate, owing to currents of air in the roum, \&c.

The results are embodied in the following Table:-

(Rate of Heating from $25^{\circ}$ to $50^{\circ}$ )

TABLE I.

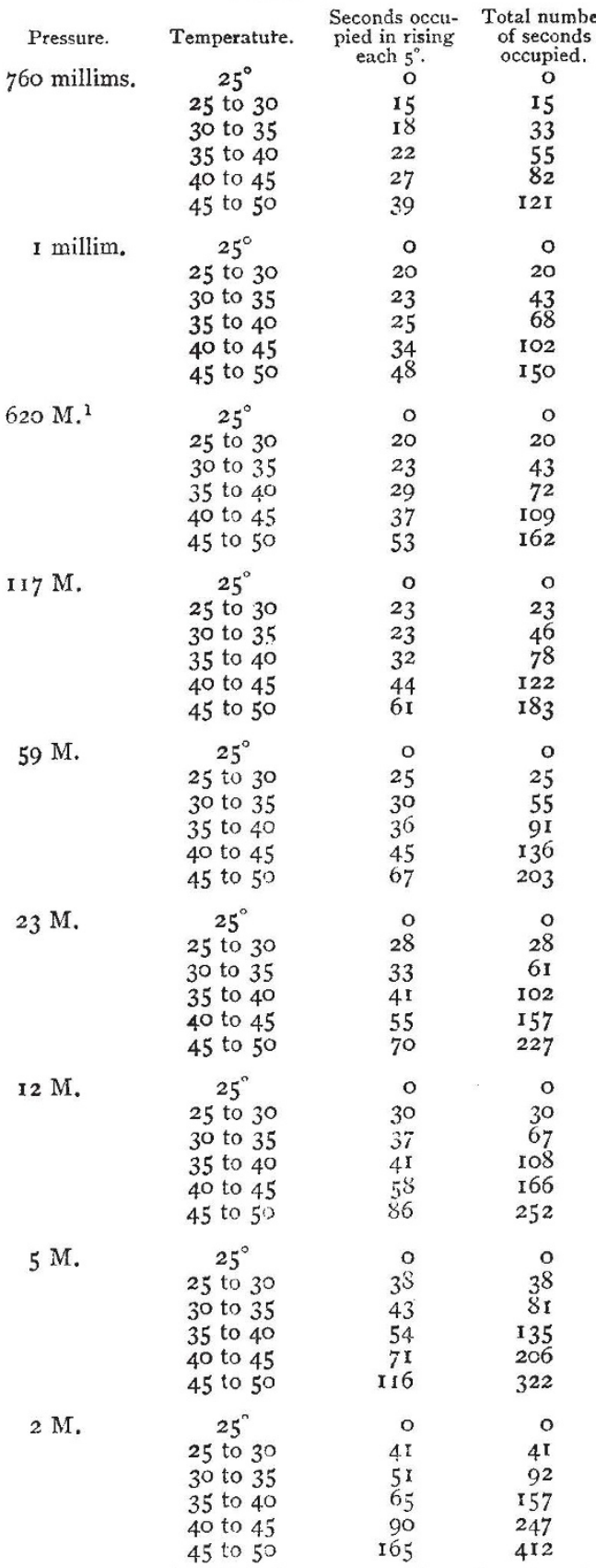

There are two ways in which heat can get from the gla:s globe to the thermometer-(I) By racliation across the intervening spince ; ( $)$ by communicating an increase of motion to the molecules of the gas, which carry it to the thermometer, It is quite conceivable that a considerable part, especially in the case of heat of low refrangibility, may be transferred by "carriage," as I will call it to distinguish it from convection which is different, and yet that we chonld not perceive much diminution of transfererce, and consequently much diminution of rate of rise with ${ }^{x} \mathrm{M}=$ millionth of an atm spliere. increased exhaustion, so long as we work with ordinary exhaustions up to I millim. or so. For if, on the one hand, there are fewer molecules impinging on the warm body (which is adverse to the carriage of heat), yet on the other the mean length of path between collisions is increased, so that the augmented motion is carried further. The number of steps by which the temperature passes from the warmer to the cooler body is diminished, and accordingly the value of each step is increased. Hence the increase in the difference of velocity before and after impact may make up for the diminution in the number of molecules impinging. It is therefore conceivable that it may not be till such high exhaustions are reached that the mean length of path between collisions becomes comparable with the dianeter of the case, that further exhaustion produces a notable fall in the rate at which heat is conveyed from the case to the thermometer.

The above experiments show that there is a notable fall, a reduction of pressure from $5 \mathrm{M}$. to $2 \mathrm{M}$. producing twice as much fall in the rate as is obtained by the whole exhaustion from 760 millims. to I millim. We may legitimately infer that each additional diminution of a millionth would produce a still greater retardation of cooling, so that in such vacua as exist in planetary space the loss of heat-which in that case would only take place by radiation-would be exceedingly slow.

\section{SCIENTIFIC SERIALS}

Fournal de Physique, December, 1880.-Note on magic mirrors, by M. Bertin.-On some applications of articulated systems, by M. Robin.-Experiments on the discharge in rarefied gases, by M. Righi.-Notice on the life and works of $M$. Almeida.

Archives des Sciences Physiques et Naturelles, November I5. - Meteorological résumé of the year 1879 for Geneva and the Great St. Bernard, by M. Plantamour.-Disinfection of vehicles, plants, collections of natural history, and various objects with anhydrous sulphurous acid, by Dr. Fatio-Observations on a memoir of M. Schönn, by M. Soret.-On the phenomenon of hydration in peptonisation of albuminoid substances, by Dr. Danilewsky. - Notes on the winds of mountains, by M. Pittier. - Case of diplopia, by Prof. Wartmann, \&c.

Reale Istituto Lombardo di Scienze e Lettere. Rendiconti. vol. xiii. fasc. xviii., November, 1880.-This number contains lists of prizes awarded and offered.

Atti della R. Accademia dei Lincei, vol. v. fasc. I (December 5,1880 ). - New studies on the nature of malaria, by SS. Cuboni and Marchiafava.-Graphic determination of the elastic force relative to plane elements passing through a point, by $\mathrm{S}$. Modigliano. - On the geological nature of strata met with in the tubular foundations of the new iron bridge built on the Tiber at Ripatta, and on the Unio simuatus, Lamk., there found, by S. Meli.On the structure of the envelope of the ova of some fishes, by S. Lepori.-On the preservation of man in countries of malaria, by $\mathrm{S}$. Tommasi-Crudeli.-On bilinear ternary forms, by $\mathrm{S}$. Battaglini.-On the projected stations for systematic physical observations in polar regions, by S. Cora.-On a cebocephalic caprine monster, by S. de Sanctis.-. On the recent restoration of the scholastic and tomistic philosophy, by S. Ferri.

\section{SOCIETIES AND ACADEMIES LONDON}

Photographic Society, December 14, 1880.-J. Glaisher, F.R.S., president, in the chair.-Papcrs were read by Prof.T. E. Thorpe, F.R.S., on a simple and expeditious method of preparing pyrogallol for dry plate development. The method proposed is to put dry gallic acid and glycerine into a flask, which is then heated to $200^{\circ}$ on a sand tray, as long as bubbles of carbon dioxide are seen to be formed in the liquid. The gallic acid soon dissolves and is entirely converted into the theoretical quantity of pyrogallol, viz., 8o per cent.-By Capt. Abney, R.E., F.R.S., iodicle and ammonia in gelatine emulsions. It was stated that iodides in gelatine bromide emulsion kept the silver salts from being depo,ited upon the sbadows, as also that there is freedom from decomposition of the film, and tendency to red fog, and more light can he used in preparing and developing the plates.-And alion by Capt. Abney on a photographic sunshine recorder. This consisted of a semi-cylindrical box with a flat lid, in the centre of which is a small hole; round the inside of the cylinder strips of sensitive paper are 